Boise State University

ScholarWorks

Human-Environment Systems Research Center

Faculty Publications and Presentations

Human-Environment Systems Research Center

8-1-2019

\title{
Bringing Forecasting into the Future: Using Google to Predict Visitation in U.S. National Parks
}

\author{
Matt Clark \\ Boise State University \\ Emily J. Wilkins \\ Utah State University \\ Dani T. Dagan \\ Kansas State University \\ Robert Powell \\ Clemson University \\ Ryan L. Sharp \\ Kansas State University
}

See next page for additional authors

\section{Publication Information}

Clark, Matt; Wilkins, Emily J.; Dagan, Dani T.; Powell, Robert; Sharp, Ryan L.; and Hillis, Vicken. (2019).

"Bringing Forecasting into the Future: Using Google to Predict Visitation in U.S. National Parks". Journal of Environmental Management, 243, 88-94. https://dx.doi.org/10.1016/j.jenvman.2019.05.006

This is an author-produced, peer-reviewed version of this article. (c) 2019, Elsevier. Licensed under the Creative Commons Attribution-Noncommercial-No Derivative Works 4.0 International license. The final, definitive version of this document can be found online at Journal of Environmental Management, doi: 10.1016/j.jenvman.2019.05.006 
Authors

Matt Clark, Emily J. Wilkins, Dani T. Dagan, Robert Powell, Ryan L. Sharp, and Vicken Hillis 


\title{
Bringing Forecasting into the Future: Using Google to Predict Visitation in U.S. National Parks
}

\author{
Matt Clark \\ Human-Environment Systems \\ Boise State University \\ Boise, ID, USA \\ and \\ Department of Biological Sciences \\ Boise State University \\ Boise, ID, USA \\ Emily J. Wilkins \\ Institute of Outdoor Recreation and Tourism, \\ Department of Environment and Society \\ Utah State University \\ Logan, UT, Australia
}

\author{
Dani T. Dagan \\ Department of Horticulture and Natural Resources \\ Kansas State University \\ Manhattan, KS, USA \\ Robert Powell \\ Department of Parks, Recreation, and Tourism \\ Management \\ Clemson University \\ Clemson, SC, USA \\ Ryan L. Sharp \\ Department of Horticulture and Natural Resources \\ Kansas State University \\ Manhattan, KS, USA
}

\author{
Vicken Hillis \\ Human-Environment Systems \\ Boise State University \\ Boise, ID, USA
}

\begin{abstract}
In recent years, visitation to U.S. National Parks has been increasing, with the majority of this increase occurring in a subset of parks. As a result, managers in these parks must respond quickly to increasing visitor-related challenges. Improved visitation forecasting would allow managers to more proactively plan for such increases. In this study, we leverage internet search data that is freely available through Google Trends to create a forecasting model. We compare this Google Trends model to a traditional autoregressive forecasting model. Overall, our Google Trends model accurately predicted $97 \%$ of the total visitation variation to all parks one year in advance from 2013-2017 and outperformed the autoregressive model by all metrics. While our Google Trends model performs better overall, this was not the case for each park unit individually; the accuracy of this model varied significantly from park to park. We hypothesized that park attributes related to trip planning would correlate with the accuracy of our Google Trends model, but none of the variables tested produced overly compelling results. Future research can continue exploring the utility of Google Trends to forecast visitor use in protected areas, or use methods demonstrated in this paper to explore alternative data sources to improve visitation forecasting in U.S. National Parks.
\end{abstract}

Keywords: internet search data; tourism demand; forecasting; Google data; park visitation; capacity

\section{Introduction}

Visitation to parks and protected areas benefits human health, local and national economies, and promotes proconservation behavior (Cullinane Thomas, Koontz, \& Cornachione, 2018; Halpenny, 2010; Maller, Townsend, Pryor, Brown, \& St Leger, 2006; Maples, Sharp, Clark, Gerlaugh, \& Gillespie, 2017). In 2017, the United States National Park Service (NPS) broadly contributed an estimated 306,000 jobs and \$35.8 billion in direct economic output; visitor spending specifically contributed to an estimated 188,600 jobs and $\$ 14.4$ billion in economic output, and visitors spent an estimated $\$ 18.2$ billion in local gateway regions (Cullinane Thomas et al., 2018). But while park visitation leads to positive outcomes for humans and economies, some argue that too many people are "loving parks to death" (e.g., Daysog, 2018; Duncan, 2016; Simmonds et al., 2018). Large numbers of visitors can stress natural, cultural, and 
This is an author-produced, peer-reviewed version of this article. The final, definitive version of this document can be found online at Journal of Environmental Management, published by Elsevier. Copyright restrictions may apply. doi: 10.1016/j.jenvman.2019.05.006

human resources, and lead to a decrease in the quality of visitor experiences (Graefe, Vaske, \& Kuss, 1984; Hallo \& Manning, 2010; Marion, Leung, Eagleston, \& Burroughs, 2016). Additionally, legal standards may be violated under rapid visitation growth scenarios. The NPS is required to identify the maximum number of visitors an area can hold without causing resource damage, and to manage visitation at or below this capacity (Cahill, Collins, McPartland, Pitt, \& Verbos, 2018), but unpredictable increases in visitation may limit mangers' ability to adhere to these standards under changing conditions. One notable example of rapid visitation increase can be seen in Joshua Tree National Park (Fig. 1) starting in 2013. In 2017, 61 of 417 areas managed by the NPS set a new record for visitation. Forty-two of these areas broke a record high set in just 2016, and between 2012 and 2017 visitation to the NPS overall grew by 17\% (National Park Service, 2018c; Ziesler \& Singh, 2018). Throughout the paper we refer to all areas managed by the National Park Service (national parks, national battlefields, national memorials, etc.) as NPS units. Without forewarning and sufficient time to prepare, a dramatic increase in visitation at an individual national park unit may necessitate that staff address only the most pressing needs, at the expense of long-term planning.

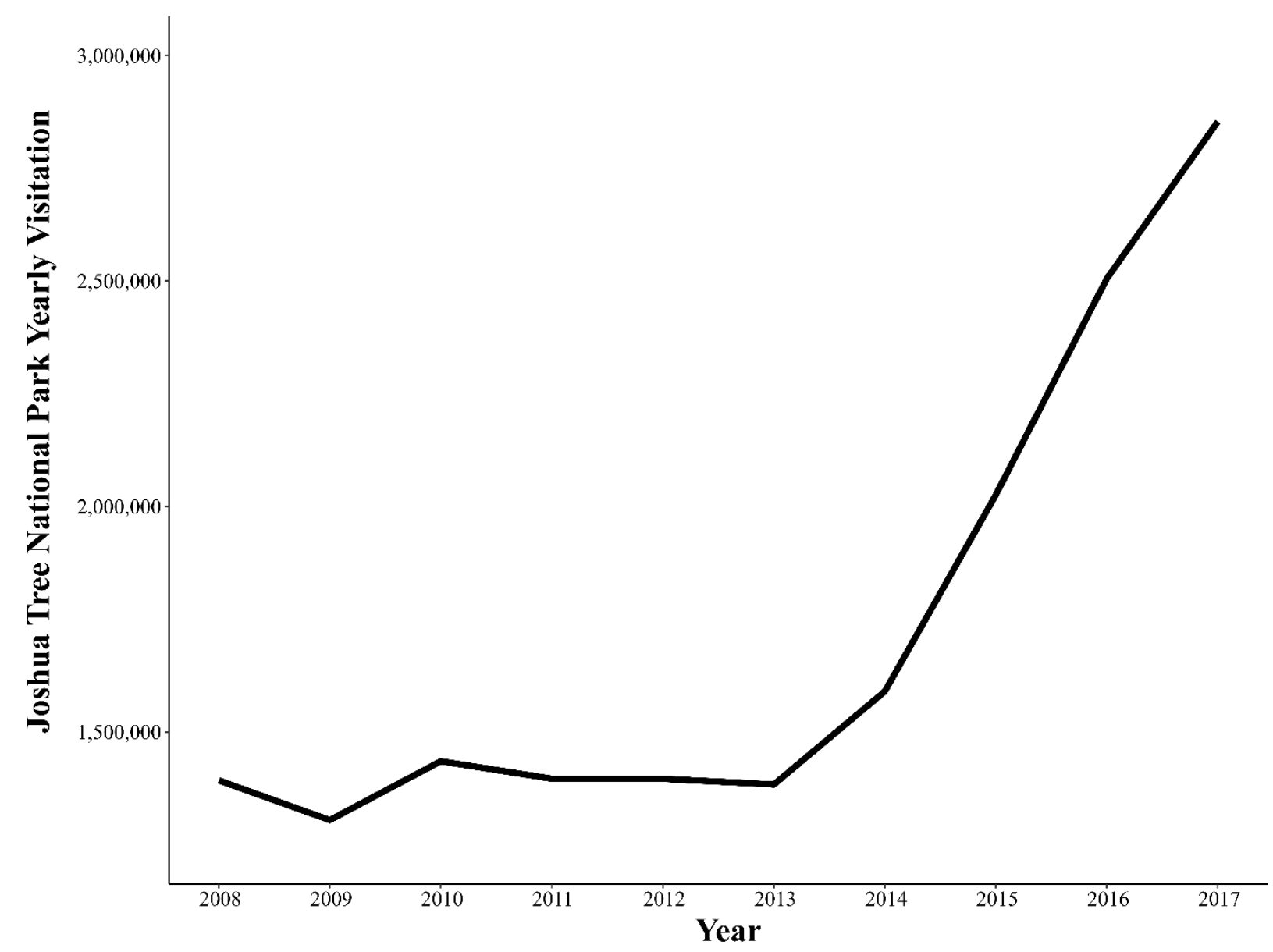

Figure 1. Time series showing yearly reported visitation to Joshua Tree National Park for 2008 - 2018. Figures showing the yearly visitation for all national parks can be found in the supplementary material at http://hillislab.boisestate.edu/GoogleTrendsForecasting/.

Presently, the NPS predicts future visitation using a model based on historic visitation from the previous five years (Ziesler, 2016). While past visitation may be a reasonably accurate predictor of future visitation, these models, often referred to as autoregressive, do not account for outside factors, such as the overall state of the economy or news \& social media attention (Wilmot \& McIntosh, 2014). Additionally, events such as hurricanes and eclipses influence visitation and are not correlated with the previous year's visitation (Ziesler \& Singh, 2018). Managers would benefit from having a more accurate method for predicting future visitation quickly and comprehensively. Improved forecasting ability could help managers better understand trends in future visitation. For example, managers could 
This is an author-produced, peer-reviewed version of this article. The final, definitive version of this document can be found online at Journal of Environmental Management, published by Elsevier. Copyright restrictions may apply. doi: 10.1016/j.jenvman.2019.05.006

assess whether a recent spike in visitation is a new baseline, a unique anomaly, or whether visitation will continue to increase. Finally, predicting visitation can help determine which management actions park officials should consider and implement.

While improved forecasting ability would enable managers to mitigate impacts of rapidly increasing visitation, it is important to recognize that limited financial or staff capacity could inhibit managers' access to collecting new data. Therefore, there is a need to explore how existing data sources can be utilized, especially those that are cheap, relatively easy to analyze, and can be collected at any time. Open-source digital data, such as those reported through Google Trends, are relatively effortless to collect and represent an opportunity for park managers to make use of search engine data. Mining digital data can be especially useful because, by analyzing the records that visitors leave behind online, it may be possible to predict changes in rates of visitation that are not captured by the current autoregressive model.

Overall, the goal of this research is not to identify the absolute best forecasting model for each and every national park unit, but rather to explore the use of easily accessible search engine data and test an alternative forecasting model which can be applied to all parks and protected areas in general. To do this, we analyzed Google Trends data for its predictive ability across U.S. National Parks; we did not include other units managed by the National Park Service such as national monuments, historic sites, etc. The specific objectives of this study are to: (1) investigate whether Google Trends is useful for predicting future visitation to U.S. National Parks as compared to an autoregressive model, and (2) explore explanations for the discrepancy in model efficacy between parks. We hypothesized that the utility of Google Trends as a predictor would not be uniform across all parks. Specifically, we speculated that our ability to use Google Trends to forecast park visitation may be affected by the proportion of people who plan their visits to each park well in advance (e.g., the previous year), operationalized as the population surrounding each park and park popularity.

\subsection{Literature Review}

A majority of Americans (86\%) use general search engines such as Google to plan travel (Fesenmaier, Xiang, Pan, \& Law, 2011). Additionally, 65\% said that general search engines were very useful or essential for planning a trip (Fesenmaier et al., 2011). Given that such a high percentage of people use general search engines to plan travel, researchers have started exploring the feasibility of using search engine data to forecast tourism arrivals (e.g. Bangwayo-Skeete \& Skeete, 2015; Dergiades, Mavragani, \& Pan, 2018; Yang, Pan, Evans, \& Lv, 2015). However, no previous study has explored using Google Trends to predict visitation to parks or protected areas. Other sources of publically available online data, such as social media, have been useful for exploring visitation to public lands (Sessions, Wood, Rabotyagov, \& Fisher, 2016; Tenkanen et al., 2017; Wood, Guerry, Silver, \& Lacayo, 2013). However, obtaining data from social media sites can be time-intensive and currently requires knowledge of how to interact with application programming interfaces (APIs). Additionally, many social media sites are now restricting access to their data. Since many public lands managers may not have time, knowledge, or access to gather this data, we explore the usability of Google Trends, which is easy and free for anyone to download.

Previous studies have explored the utility of using Google Trends to forecast a range of social phenomena, including flu-related emergency room visits, cinema admissions, private consumption, and tourist demand (Araz, Bentley, \& Muelleman, 2014; Hand \& Judge, 2012; Önder \& Gunter, 2016; Vosen \& Schmidt, 2011). Search engine data has numerous advantages, including the ability to track preferences in real time and providing a high frequency of data (Yang et al., 2015). In one of the earliest studies investigating the utility of Google Trends, Choi and Varian (2012) found that Google Trends was useful for predicting present conditions in a variety of contexts, such as sales of motor vehicles and parts, claims for unemployment, and predicting visitors to Hong Kong. However, the authors state that more research is needed to explore whether this data would be useful for making future projections (Choi \& Varian, 2012).

After Choi and Varian's initial finding that Google Trends may be useful for tourism, more researchers started to explore ways to use this data. Bangwayo-Skeete and Skeete (2015) tested whether Google search data can predict visitor arrivals at popular tourist destinations in the Caribbean Islands, and found that Google search data significantly improved the ability of models to forecast future visitation. Additionally, Li, Pan, Law, and Huang (2017) found that using a search index to forecast future tourism demand in Beijing was more accurate than traditional models using past visitation alone. Park, Lee, and Song (2017) also found that models using Google Trends to forecast short-term tourism inflows to South Korea performed better than traditional time-series models. However, Dergiades et al. (2018) 
This is an author-produced, peer-reviewed version of this article. The final, definitive version of this document can be found online at Journal of Environmental Management, published by Elsevier. Copyright restrictions may apply. doi: 10.1016/j.jenvman.2019.05.006

noted that using search engine data to forecast tourism is often filled with language and platform bias, particularly for destinations that have many international visitors. Not all visitors use the same search engines or search for things in the same languages.

This body of literature shows that search engine data can be highly useful for forecasting tourism demand. However, it is uncertain how well this data can predict visitation to parks and protected areas specifically. These visitors may have different search habits than visitors to big cities or hotels. Google Trends data has the potential to improve current visitation forecasting methods by capturing trends in social media, news media, and other cultural or social shifts that influence public desire to plan and subsequently visit any given park unit. Google Trends therefore may represent the culmination of these various social phenomena, but further research is necessary to better understand the utility of this emerging tool.

\section{Methodology}

\section{$\underline{2.1 \text { Study Sites }}$}

The U.S. National Park Service (NPS) has 60 units designated as National Parks. Two of these sites were not included in this study because of their recent designations (Pinnacles and Gateway Arch, which were designated in 2013 and 2018 respectively). The relatively new designations did not allow enough historical data for modeling. One site, National Park of American Samoa, does not have visitation data for 2008 - 2010, and was therefore also not included in this study. The 57 parks studied collectively had 85.2 million visits in 2017 (National Park Service, 2018b). National Parks were chosen as opposed to other units managed by the National Park Service because they have the most reliable visitation data, the highest numbers of visitors, the highest economic and cultural impact, and have seen unprecedented visitation changes in recent years (Ziesler \& Singh, 2018).

\subsection{Data Collection}

All data used in this paper is readily available through an open source application found here: http://hillislab.boisestate.edu/GoogleTrendsForecasting/. This application was created using the 'shiny' package for the 'R' statistical platform (Chang, Cheng, Allaire, Xie, \& McPherson, 2018).

\subsubsection{Park Visitation}

We retrieved data on historic park visitation from the National Park Visitor Use Statistics Portal (National Park Service, 2018c). Methods for collecting these data generally include the use of car counters, concessioner reports, and permit information, but are specific to each NPS unit. Unit-specific protocols can be found on the NPS Visitor Use Statistics website (https://irma.nps.gov/Stats/) (Ziesler \& Singh, 2018). We downloaded monthly visitation data for each of the 57 U.S. National Parks from 2006 - 2017; we then summed all months into yearly counts to avoid confounding seasonal variation and increase the interpretability of this research. Although we believe some reported visitation counts may be erroneous (e.g. “0”), we took all data as is.

\subsubsection{Google Trends}

We downloaded search history data for each national park individually from 2007 - 2017 using the Google Trends interface, which can be accessed at https://trends.google.com/trends/. These data are reported and were downloaded at the monthly scale for each park. For most search terms, data is available from 2004 - present. In order to complete the search instantly, Google analyzes a sample of the total volume of searches and the data is then indexed from 0 to 100 , where 100 is the highest volume of searches for the selected range. A value of 50 indicates there are half as many searches for the term that month compared to the month indexed at 100. In summary, the indexed Google Trends data represents the total number of people searching for the specified term, compared to the total volume of searches in the selected area, scaled such that the highest value in the selected time frame is set to 100.

Google Trends provides the option to track either search terms or topics. While search terms represent only those who type in the exact phrase in a specified language, topics represent anyone searching for the specified concept, in any language. We therefore used topics rather than search terms due to the ability to capture a broader array of searches in other languages and reduce bias. We also set Google Trends to provide data based on worldwide searches, since many U.S. National Parks host international visitors. 
This is an author-produced, peer-reviewed version of this article. The final, definitive version of this document can be found online at Journal of Environmental Management, published by Elsevier. Copyright restrictions may apply. doi: 10.1016/j.jenvman.2019.05.006

\subsubsection{Spatial Data}

We downloaded two sets of spatial data for this study to explore our second research question. The first dataset included shapefiles of the locations of each national park in the U.S., which we downloaded from the NPS (National Park Service, 2018a). We also downloaded 2010 U.S. census block data from ESRI Data \& Maps (ESRI, 2018).

\subsection{Data Analysis}

\subsubsection{Modeling}

In this study, we created an autoregressive model to compare against our predictions using Google Trends values alone. We created our own autoregressive model, rather than comparing our projections to those of the National Park Service, to establish that the variation in model accuracies are a result of the predictive variable (Google Trends vs. past visitation), rather than statistical methods. By creating our own autoregressive model, we can ensure that we are comparing parallel methodologies and achieving the greatest level of interpretability and contrast between the two models.

Our autoregressive model predicts the expected visitation for each specific park for a given year (yi) based on the visitation to that specific park from the five previous years:

$$
\mathrm{X}_{\text {Vis t-1 }}, \mathrm{X}_{\text {Vis t-2 }}, \mathrm{X}_{\text {Vis t-3 }}, \mathrm{X}_{\text {Vis t-4 }}, \mathrm{X}_{\text {Vis t-5 }}
$$

We chose a 5-year autoregressive interval because this is the interval used by the National Park Service for forecasting, although they use a simple trend line extension based on the last 5 years of visitation (Ziesler, 2016). We used a hierarchical model structure to allow each park to retain its own intercept in the equation ( $\left(\beta 0_{\text {Park }[i]}\right)$. We fit this model to a negative binomial distribution in a Bayesian framework. We chose a negative binomial distribution as opposed to a Poisson distribution for these models because the negative binomial distribution includes a term $(\phi)$ to account for overdispersion, or high amounts of variability between parks (Gardner, Mulvey, \& Shaw, 1995). We constructed these models with the 'rstanarm' package in the R statistical programming language (Goodrich, Gabry, Ali, \& Brilleman, 2018). A Bayesian model is preferred to a frequentist model in this situation because it offers greater flexibility when assessing predictor and outcome variables which are on considerably different scales (e.g. Google Trends values and park visitation) (Clark, 2005).

$$
\begin{gathered}
\text { yi } \sim \mathrm{NB}(\mu \mathrm{i}, \phi) \\
\log (\mu \mathrm{i})=\beta 0+\beta 0_{\text {Park[i] }}+\beta 1 * \mathrm{X}_{\text {Vis t-1 }}+\beta 2 * \mathrm{X}_{\text {Vis t-2 }}+\beta 3 * \mathrm{X}_{\text {Vis } t-3}+\beta 4 * \mathrm{X}_{\text {Vis t-4 }}+\beta 5 * \mathrm{X}_{\text {Vis t-5 }}
\end{gathered}
$$

Our Google Trends model has a similar overall structure, although it uses a specific Google Trends parameter, or slope estimate for each park ( $\left.\beta 1_{\text {Park[i] }}\right)$ to predict visitation, and is informed by the sum of the Google Trends values for each park one year previous to the year being predicted $\left(\mathrm{X}_{\mathrm{Google}}\right)$, rather than by previous visitation.

$$
\begin{gathered}
\mathrm{yi} \sim \mathrm{NB}(\mu \mathrm{i}, \phi) \\
\log (\mu \mathrm{i})=\beta 0+\beta 0_{\text {Park[i] }}+\beta 1 * \mathrm{X}_{\text {Google }}+\beta 1_{\text {Park[i] }} * \mathrm{X}_{\text {Google }}
\end{gathered}
$$

Both the autoregressive and Google Trends models predict park visitation on the annual scale, one year in advance. For example, when we are predicting visitation for 2015, we are only using visitation through 2014 and Google Trends values through 2014 for the autoregressive and Google Trends models respectively.

For both models, we used the default weakly informative prior distributions in the 'rstanarm' package (Goodrich et al., 2018). The default priors for both the intercept and all coefficients, are normally centered at 0 , with a standard deviation of 10 and 2.5 for the intercept and coefficients respectively. The default weakly informative error standard deviation or "sigma" is exponential. These prior distributions were chosen because they are extremely conservative. The package automatically rescales these priors if necessary to match the order of magnitude of the data. Our autoregressive model did not require any rescaling, so the default priors were kept. The Google Trends model rescaled the standard deviation of our Google Trends coefficient only; the rescaled standard deviation was 0.017. Both models showed adequate mixing and Markov Chain convergence. 
This is an author-produced, peer-reviewed version of this article. The final, definitive version of this document can be found online at Journal of Environmental Management, published by Elsevier. Copyright restrictions may apply. doi: 10.1016/j.jenvman.2019.05.006

\subsubsection{Validation}

To assess the out-of-sample predictive ability of both models, we blocked all data from 2013 - 2017 by year so that each block contains the data for all parks for that year. We then used all data prior to that year to inform or "train" predictions for that block. As we progressed through the blocks, we included blocks prior to the year being predicted or "tested.” (Fig. 2). This procedure is often called cross-validation on a rolling basis. We chose to validate our models in this way because it allowed us to make use out of all available data, while not informing any predictions based on present or future data (Bergmeir \& Benítez, 2012). It is in this same vein that we blocked our data by entire years, as opposed to by both park and year. This prevented the models from using any present or future data, even those from other parks.

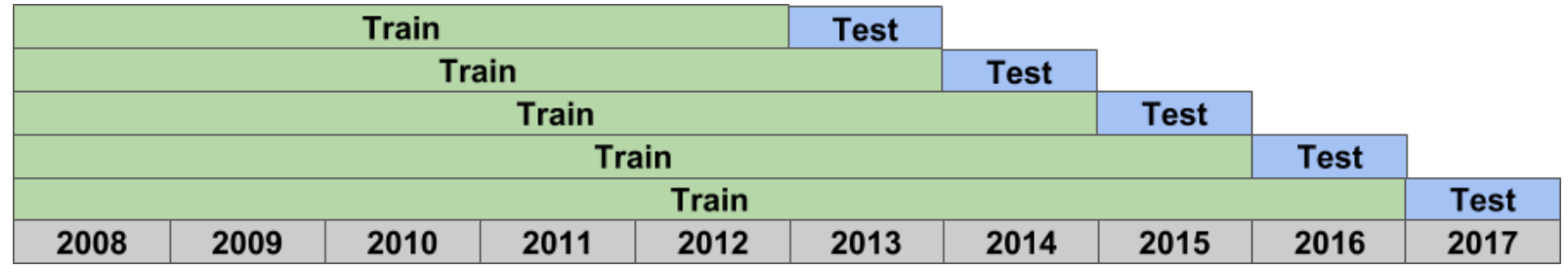

Figure 2. Our implementation of cross-validation on a rolling basis.

\subsubsection{Error}

We specified our models to yield 2,000 visitation predictions for each park, for each year. We took the median of these predictions as our projected visitation forecast. All error metrics were calculated based on these median predictions compared to the observed visitation for each park. We chose to use three different metrics to test the accuracy of our median predictions. These included $\mathrm{R}^{2}$, sometimes referred to as the coefficient of determination, the mean absolute error (MAE), and mean percent variation from the observed visitation, or mean percent error. The first two metrics were used to compare the overall accuracy of our predictions (median prediction) for all parks, and the latter two were used to test the accuracy of our median predictions for each park individually. $\mathrm{R}^{2}$ is a useful measure for comparing overall model accuracy (Fig. 3), but is unreliable for small sample sizes (e.g. park specific error). $\mathrm{R}^{2}$ also assumes a normal distribution for all data, which is not met for the park specific data, further highlighting the limitation of this metric for park specific error estimation (The Pennsylvania State University, 2018). To compare the error for specific parks, we use the other two metrics. For transparency, the $\mathrm{R}^{2}$ for specific parks is provided on the error metrics page of the supplementary online application, but we do not recommend using this as an accuracy metric for the reasons stated above. We do not use mean percent error to measure overall model error because summing total visitation and total model predictions to calculate this would result in information on small parks being dominated by larger parks.

\subsubsection{Exploratory Analysis}

With model results in hand, we explored under what conditions Google Trends accurately forecasted national park visitation. We hypothesized model accuracy would be influenced by both the population surrounding each park and park popularity; we used average visitation as an analog for park popularity. We found the population within 50 miles (80.5 km) of each park by creating a 50-mile buffer around each park area using ArcGIS and summing the populations of all 2010 census blocks for which the centroid was located inside the buffer area.

To explore these hypotheses, we ran correlation tests, looking at the association between both the mean park visitation (Fig. 5A) and the total population within 50 miles ( $80.5 \mathrm{~km}$ ) of each park (Fig. 5B), and the mean percent error between our median visitation prediction and the observed visitation for each park.

\section{Results}

\subsection{Overall Model Accuracy}

We calculated the mean absolute error (MAE), and $\mathrm{R}^{2}$ between the observed visitation and the median prediction for all parks, for all years (2013 - 2017) for both models. Our Google Trends model outperformed our autoregressive model by both metrics (Table 1 ). 
This is an author-produced, peer-reviewed version of this article. The final, definitive version of this document can be found online at Journal of Environmental Management, published by Elsevier. Copyright restrictions may apply. doi: 10.1016/j.jenvman.2019.05.006

Table 1: Overall error metrics for autoregressive and Google Trends median model predictions

\begin{tabular}{lll}
\hline Model & MAE & $\mathbf{R}^{2}$ \\
\hline Google Trends & 202,080 & 0.977 \\
Autoregressive & 230,547 & 0.867 \\
\hline
\end{tabular}

Overall, our Google Trends model explains $97.7 \%$ of all variation in National Park visitation (Fig. 3A). Compared to our autoregressive model, which explains $86.7 \%$ of all variation (Fig. 3B), the Google Trends model is much more consistent; especially when predicting high visitation numbers.

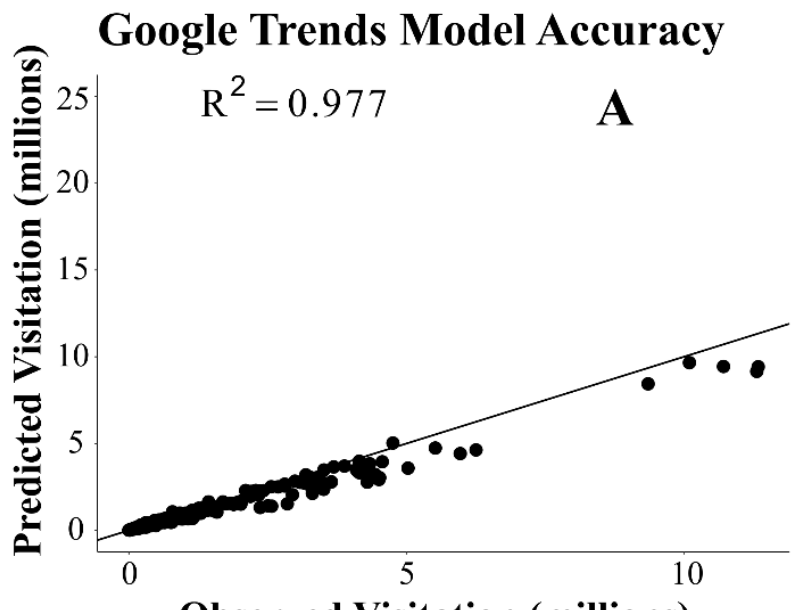

Observed Visitation (millions)

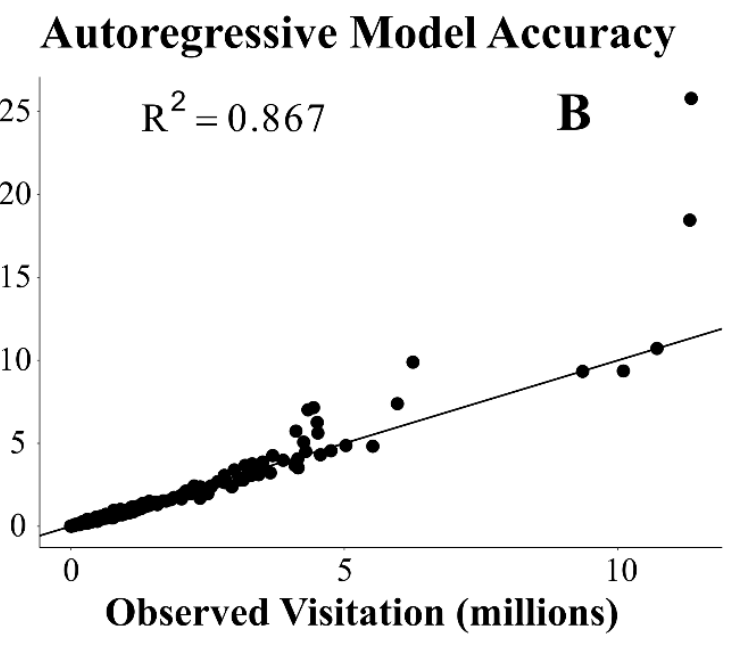

Figure 3. Scatterplots showing observed vs predicted visitation using the Google Trends model (Fig. A) and autoregressive model (Fig. B). The lines represent a 1:1 line of perfect fit. An interactive version of these plots (showing the year and park for each data point) is available at http://hillislab.boisestate.edu/GoogleTrendsForecasting/.

\subsection{Park-Specific Accuracy}

We calculated the MAE and mean percent error (Fig. 4) between the observed visitation and the median prediction for each park, for all years (2013 - 2017) for both models (S1). At the park level, both the Google Trends and autoregressive models showed considerable variation in accuracy. Our autoregressive model produced a mean percent error that ranged from $4.37 \%$ to $39.61 \%$ for individual parks. For our Google Trends model, the low and high of this metric were $3.51 \%$ and $26.31 \%$ respectively. These values can be interpreted as follows: on the scale of the observed visitation, on average for all modeled years, how much higher or lower were the model projections for that specific park from the real visitation.

We also show the MAE for each specific park. Because MAE is highly correlated with the scale of the data (Willmott \& Matsuura, 2005), we suggest that MAE should be used only to compare between models for individual parks, rather than between parks (i.e. larger parks will tend to naturally have larger MAE). For this reason, we compare predictions between parks using the mean percent error (Fig. 4). 
This is an author-produced, peer-reviewed version of this article. The final, definitive version of this document can be found online at Journal of Environmental Management, published by Elsevier. Copyright restrictions may apply. doi: 10.1016/j.jenvman.2019.05.006

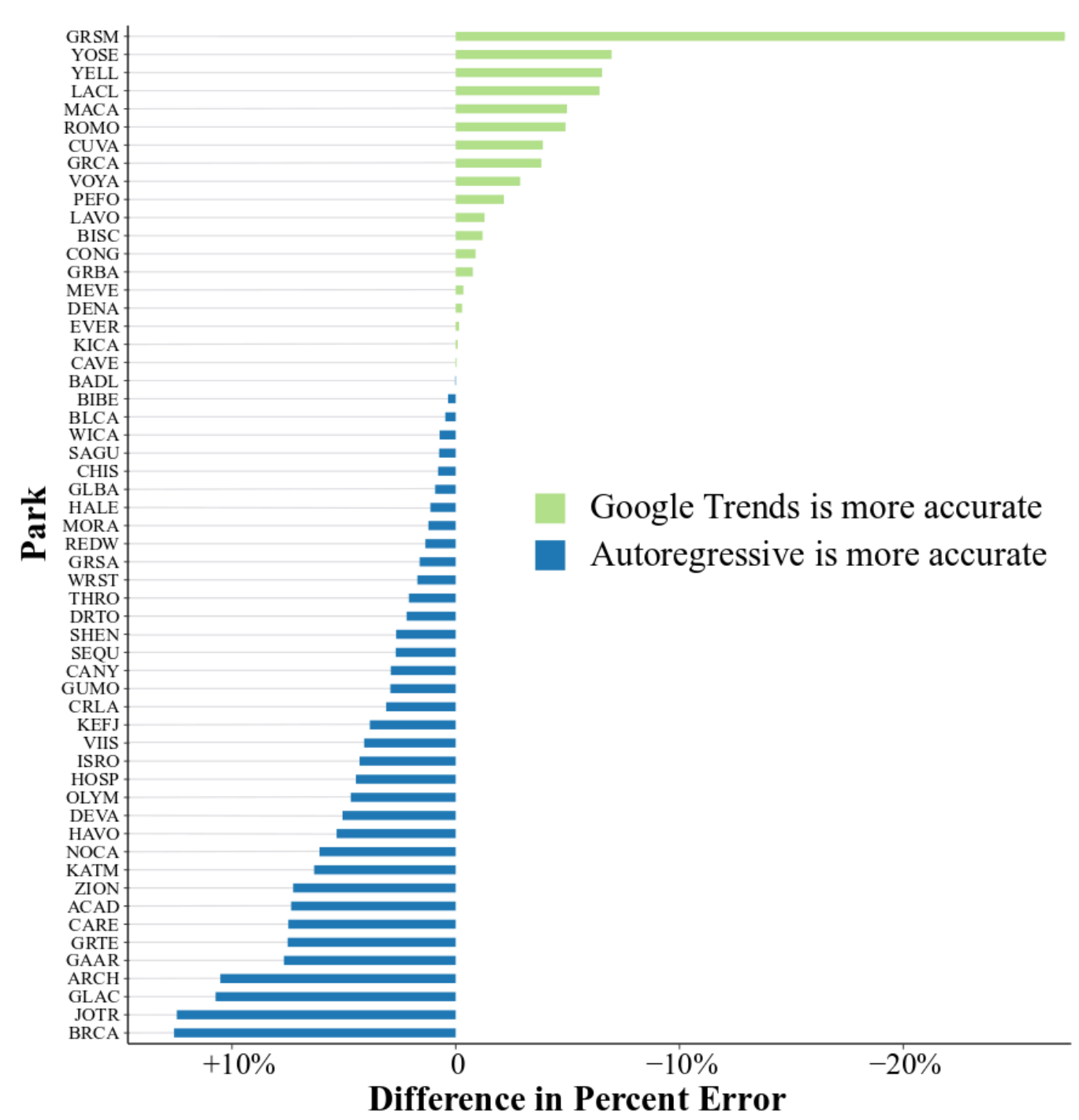

Figure 4. Difference in mean percent error between the Google Trends and autoregressive models, by national park. The full park name associated with each 4-letter code can be found on the online application (http://hillislab.boisestate.edu/GoogleTrendsForecasting/) under the tab "Unit code key \& population data.”

For the majority of national parks individually, our autoregressive model outperformed our Google Trends model. In these cases, where the autoregressive model is preferred, it is from $0.34 \%$ to $12.6 \%$ more accurate than the Google Trends model. In cases where the Google Trends model outperforms the autoregressive model, it is $0.03 \%$ to $27.2 \%$ more accurate.

\section{$\underline{3.3 \text { Exploratory Results }}$}

Exploratory analyses examining which factors might influence the accuracy of Google Trends model predictions were largely insignificant. The mean yearly visitation to each park yielded an insignificant correlation of -0.07 with the mean percent error of each park (Fig. 5A). When we calculated the same metric for population within 50 miles of each park, we produced a weak correlation of -0.31 (Fig. 5B). 
This is an author-produced, peer-reviewed version of this article. The final, definitive version of this document can be found online at Journal of Environmental Management, published by Elsevier. Copyright restrictions may apply. doi: 10.1016/j.jenvman.2019.05.006
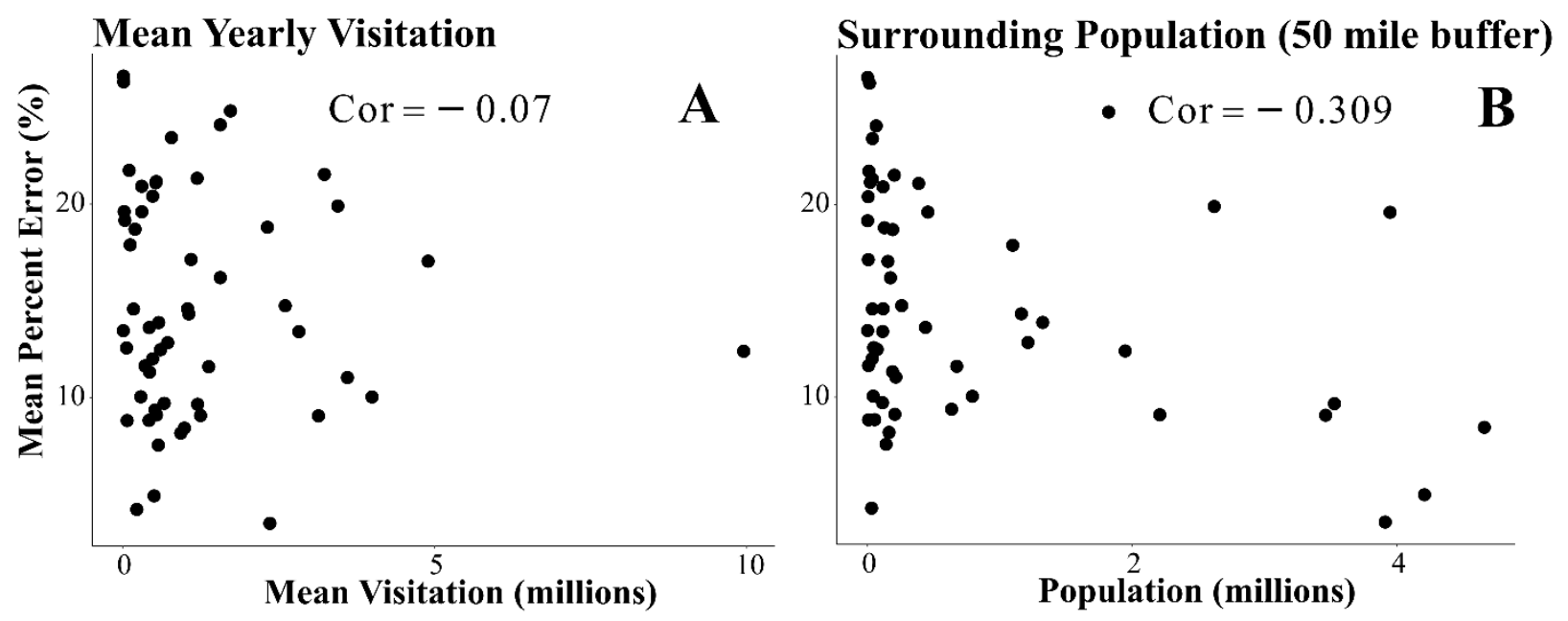

Figure 5. Correlations between the mean percent error of the Google Trends model and mean park visitation (Fig. A) and population within 50 miles of the park (Fig B). Each point represents one national park.

\section{Discussion}

Our study found that Google Trends is a useful tool for forecasting future visitation at U.S. National Parks. As with previous studies, which demonstrate that search engine volume is a useful indicator of future tourism arrivals (Bangwayo-Skeete \& Skeete, 2015; Dergiades, Mavragani, \& Pan, 2018; Yang, Pan, Evans, \& Lv, 2015), we show that Google Trends can perform well in the context of U.S. National Parks. This is true despite the factors that make park visitation different from general tourism arrivals, such as limited cellular or internet service, or differences in planning behaviors. However, this study does not suggest that Google Trends is always a better tool than previously established models; rather, we encourage consideration of these data as a supplemental resource where appropriate. We speculate that Google data is most useful when park visitation is measured consistently, and given Google's status as a leading search engine. Futher, we aimed to demonstrate a method for testing the usefulness of mining search engine data for park settings, and suggest that future research continue exploring how and when these data sources can augment or update present visitation forecasting efforts.

While our Google Trends model performed better than our autoregressive model overall, the autoregressive model performed better for a higher number of individual parks. To explain these differences, we predicted that factors related to pre-trip planning (i.e. nearby population) and popularity of parks (i.e. number of visitors) would correlate with the accuracy of the Google Trends model; we expected that parks with smaller proximate populations and higher visitation would be searched more often in the pre-planning phase, and thus the Google Trends model would perform better for those parks. However, only one of these factors (nearby population) correlated loosely (cor $=-0.31$ ) with forecasting accuracy, and the relationship was the opposite of what we hypothesized (Fig. 5B). This correlation indicates that Google Trends was a slightly better predictor in parks that had larger nearby populations compared to parks with smaller nearby populations. Our hypothesis that the magnitude of visitation would impact the efficacy of our Google Trends model resulted with an insignificant correlation of -0.07 . This suggests that the utility of Google Trends as a predictor is unaffected by the number of visitors a park receives. We found no minimum visitation threshold for this model to be useful.

It also appears that previous growth rate contributes to the discrepancy in model performance. The autoregressive model, although extremely accurate for the majority of parks, shows a tendency to predict unrealistically high levels of visitation (e.g. >12 million visitors) for years following visitation spikes in large parks. This tendency appears to explain the majority of the error in the autoregressive model.

\subsection{Limitations and Future Research}

A significant limitation when considering Google Trends data, especially from the practitioner perspective, results from how Google reports the data. Google Trends does not report raw numbers, but rather rescales values between 1 and 100 , where 100 is always the highest volume of searches for the selected time range. This means that every time 
This is an author-produced, peer-reviewed version of this article. The final, definitive version of this document can be found online at Journal of Environmental Management, published by Elsevier. Copyright restrictions may apply. doi: 10.1016/j.jenvman.2019.05.006

there is a new high in Google search interest included in a user's search parameters, the data will rescale. In other words, the values Google reports may vary based on the time range selected. It is therefore not possible to create a permanent database of trend numbers, nor is it possible to make an assessment about visitation based on a single number. Any given value on Google Trends lacks meaning alone, but rather needs to be interpreted in the context of trends over time. Additionally, values cannot be compared across search topics or time frames and it cannot be assumed that a certain value means the same thing each time Google Trends data are viewed. Alternatively, access to the algorithm, or collaboration with Google, may allow researchers to use the raw search data and yield numbers that can be used by practitioners.

Additionally, the accuracy of visitation data reported by the National Park Service (NPS) may affect the predictive ability of these models. For example, Kobuk Valley National Park reports zero visitors in 2014 and 2015. Because we used a hierarchical approach where all park predictions borrow strength from each other, the impact of a few inaccurate parks may impact the model's ability to predict for other parks (Steenbergen \& Jones, 2002). Future research could couple the visitation data reported by the NPS with other sources, such as interviews with NPS staff, to build more accurate estimates of yearly park visitation.

Another limitation of using Google Trends is that countries, which do not use Google would not be accounted for in a Google Trends model. While the use of Google "topics" rather than search terms accounts for language differences, visitors from those nations where use of Google is restricted or uncommon would not be included in forecasting calculations. Future research can delve into the applicability of Google Trends for specific types of cases by applying U.S. only searches, rather than international searchers, for parks that see low international visitation.

Future research into Google Trends can also experiment with smaller temporal scales, such as weekly or monthly data, or spatial scales, such as sites within parks or larger geographic regions. Smaller time scales may also allow researchers to test the hypothesis that Google Trends can be used to predict visitation changes as a direct result of acute events (e.g. superblooms, wildfire, or news \& social media attention). Researchers could also explore what lag times exist between Google searching and visitation; for example, they could use questionnaires to determine how far in advance people begin researching their destination park via Google, perhaps exploring whether visitors to certain parks begin trip planning sooner. Since this study used search data from the current year to predict visitation the following year, we assumed some visitors would be searching for information about a park the year prior to visiting. Finally, future research may test alternative hypotheses as to when and why Google Trends models perform better or worse than autoregressive models.

\subsection{Management Implications}

Due to the limitations outlined above, we do not recommend managers substitute current autoregressive forecasting with Google Trends modeling. However, managers may consider Google Trends, or similar search volume data, as part of a mosaic of data informing expectations of future conditions. Additionally, parks and protected area managers who do not have access to forecasting tools due to time or monetary constraints, can monitor Google Trends to gain an idea of future visitation volume, particularly as it relates to past trends.

\section{Conclusions}

While the Google Trends model constructed for this study performed better than our autoregressive model overall, it does not necessarily follow that Google Trends is a superior tool for modeling individual U.S. National Parks. Instead, we suggest that Google Trends, or other search engine volume metrics, be considered when modeling future visitation, and utilized in part or in full when appropriate. Further research is needed to further explore this tool, as well as address limitations. Finally, future research may employ the methods presented in this paper to test new and emerging data sources related to visitor volume, density, spatiotemporal distribution, and more.

\section{Supplementary Material}

S1. The RShiny app can be found here: http://hillislab.boisestate.edu/GoogleTrendsForecasting/. This app contains all of the data used, interactive figures, model validation figures by park, a forecast explorer tool, error metric for both models, and a key detailing the park name associated with each 4-letter unit code. 
This is an author-produced, peer-reviewed version of this article. The final, definitive version of this document can be found online at Journal of Environmental Management, published by Elsevier. Copyright restrictions may apply. doi: 10.1016/j.jenvman.2019.05.006

\section{Acknowledgements}

This project was inspired by the 2018 George Wright Society Park Break. We thank the National Park Service and the George Wright Society for providing funding and an opportunity to learn about the management challenges of national parks. We also thank James Nelson and Charlie Becker at Boise State University for help creating the interactive application that accompanies this paper.

\section{Funding Sources}

Funding for this project is provided by: NSF Idaho EPSCoR Award No. IIA-1301792. This research was also funded in part by the National Park Service and The George Wright Society. Emily J. Wilkins received support from the National Science Foundation under Grant No. 1633756.

\section{References}

Araz, O. M., Bentley, D., \& Muelleman, R. L. (2014). Using Google Flu Trends data in forecasting influenza-likeillness related ED visits in Omaha, Nebraska. The American Journal of Emergency Medicine, 32(9), 10161023.

Bangwayo-Skeete, P. F., \& Skeete, R. W. (2015). Can Google data improve the forecasting performance of tourist arrivals? Mixed-data sampling approach. Tourism Management, 46, 454-464.

Bergmeir, C., \& Benítez, J. M. (2012). On the use of cross-validation for time series predictor evaluation. Information Sciences, 191, 192-213.

Cahill, K., Collins, R., McPartland, S., Pitt, A., \& Verbos, R. (2018). Overview of the Interagency Visitor Use Management Framework and the Uses of Social Science in its implementation in the National Park Service. The George Wright Society Forum, 35(1), 32-41.

Chang, W., Cheng, J., Allaire, J. J., Xie, Y., \& McPherson, J. (2018). Shiny: web application framework for R. https://CRAN.R-project.org/package=shiny

Choi, H., \& Varian, H. (2012). Predicting the present with Google Trends. Economic Record, 88, 2-9.

Clark, J. S. (2005). Why environmental scientists are becoming Bayesians. Ecology letters, 8(1), 2-14.

Cullinane Thomas, C. L., Koontz, L., \& Cornachione, E. (2018). 2017 national park visitor spending effects: Economic contributions to local communities, states, and the nation. Retrieved from Fort Collins, CO:

Daysog, R. (2018). Are people loving Hanauma Bay to death? A new study is trying to answer that question. Retrieved from http://www.hawaiinewsnow.com/2018/11/14/are-people-loving-hanauma-bay-death-newstudy-is-trying-answer-that-question/

Dergiades, T., Mavragani, E., \& Pan, B. (2018). Google Trends and tourists' arrivals: Emerging biases and proposed corrections. Tourism Management, 66, 108-120.

Duncan, D. (2016). Are we loving our National Parks to death? Retrieved from https://www.nytimes.com/2016/08/07/opinion/sunday/are-we-loving-our-national-parks-to-death.html

ESRI. (2018). USA Census Block Group Boundaries. Retrieved from http://www.arcgis.com/home/item.html?id=1c924a53319a491ab43d5cb1d55d8561

Fesenmaier, D. R., Xiang, Z., Pan, B., \& Law, R. (2011). A framework of search engine use for travel planning. Journal of Travel Research, 50(6), 587-601.

Gardner, W., Mulvey, E. P., \& Shaw, E. C. (1995). Regression analyses of counts and rates: Poisson, overdispersed Poisson, and negative binomial models. Psychological bulletin, 118(3), 392.

Goodrich, B., Gabry, J., Ali, I., \& Brilleman, S. (2018). rstanarm: Bayesian applied regression modeling via Stan. http://mc-stan.org/

Graefe, A. R., Vaske, J. J., \& Kuss, F. R. (1984). Social carrying capacity: An integration and synthesis of twenty years of research. Leisure Sciences, 6(4), 395-431.

Hallo, J. C., \& Manning, R. E. (2010). Analysis of the social carrying capacity of a national park scenic road. International Journal of Sustainable Transportation, 4(2), 75-94.

Halpenny, E. A. (2010). Pro-environmental behaviours and park visitors: The effect of place attachment. Journal of Environmental Psychology, 30(4), 409-421. doi:10.1016/j.jenvp.2010.04.006

Hand, C., \& Judge, G. (2012). Searching for the picture: forecasting UK cinema admissions using Google Trends data. Applied Economics Letters, 19(11), 1051-1055.

Li, X., Pan, B., Law, R., \& Huang, X. (2017). Forecasting tourism demand with composite search index. Tourism Management, 59, 57-66. 
This is an author-produced, peer-reviewed version of this article. The final, definitive version of this document can be found online at Journal of Environmental Management, published by Elsevier. Copyright restrictions may apply. doi: 10.1016/j.jenvman.2019.05.006

Maller, C., Townsend, M., Pryor, A., Brown, P., \& St Leger, L. (2006). Healthy nature healthy people: contact with nature'as an upstream health promotion intervention for populations. Health promotion international, 21(1), 45-54.

Araz, O. M., Bentley, D., \& Muelleman, R. L. (2014). Using Google Flu Trends data in forecasting influenza-likeillness related ED visits in Omaha, Nebraska. The American Journal of Emergency Medicine, 32(9), 10161023.

Bangwayo-Skeete, P. F., \& Skeete, R. W. (2015). Can Google data improve the forecasting performance of tourist arrivals? Mixed-data sampling approach. Tourism Management, 46, 454-464.

Bergmeir, C., \& Benítez, J. M. (2012). On the use of cross-validation for time series predictor evaluation. Information Sciences, 191, 192-213.

Cahill, K., Collins, R., McPartland, S., Pitt, A., \& Verbos, R. (2018). Overview of the Interagency Visitor Use Management Framework and the Uses of Social Science in its implementation in the National Park Service. The George Wright Society Forum, 35(1), 32-41.

Chang, W., Cheng, J., Allaire, J. J., Xie, Y., \& McPherson, J. (2018). Shiny: web application framework for R. https://CRAN.R-project.org/package=shiny

Choi, H., \& Varian, H. (2012). Predicting the present with Google Trends. Economic Record, 88, 2-9.

Clark, J. S. (2005). Why environmental scientists are becoming Bayesians. Ecology letters, 8(1), 2-14.

Cullinane Thomas, C. L., Koontz, L., \& Cornachione, E. (2018). 2017 national park visitor spending effects: Economic contributions to local communities, states, and the nation. Retrieved from Fort Collins, CO:

Daysog, R. (2018). Are people loving Hanauma Bay to death? A new study is trying to answer that question. Retrieved from http://www.hawaiinewsnow.com/2018/11/14/are-people-loving-hanauma-bay-death-newstudy-is-trying-answer-that-question/

Dergiades, T., Mavragani, E., \& Pan, B. (2018). Google Trends and tourists' arrivals: Emerging biases and proposed corrections. Tourism Management, 66, 108-120.

Duncan, D. (2016). Are we loving our National Parks to death? Retrieved from https://www.nytimes.com/2016/08/07/opinion/sunday/are-we-loving-our-national-parks-to-death.html

ESRI. (2018). USA Census Block Group Boundaries. Retrieved from http://www.arcgis.com/home/item.html?id=1c924a53319a491ab43d5cb1d55d8561

Fesenmaier, D. R., Xiang, Z., Pan, B., \& Law, R. (2011). A framework of search engine use for travel planning. Journal of Travel Research, 50(6), 587-601.

Gardner, W., Mulvey, E. P., \& Shaw, E. C. (1995). Regression analyses of counts and rates: Poisson, overdispersed Poisson, and negative binomial models. Psychological bulletin, 118(3), 392.

Goodrich, B., Gabry, J., Ali, I., \& Brilleman, S. (2018). rstanarm: Bayesian applied regression modeling via Stan. http://mc-stan.org/

Graefe, A. R., Vaske, J. J., \& Kuss, F. R. (1984). Social carrying capacity: An integration and synthesis of twenty years of research. Leisure Sciences, 6(4), 395-431.

Hallo, J. C., \& Manning, R. E. (2010). Analysis of the social carrying capacity of a national park scenic road. International Journal of Sustainable Transportation, 4(2), 75-94.

Halpenny, E. A. (2010). Pro-environmental behaviours and park visitors: The effect of place attachment. Journal of Environmental Psychology, 30(4), 409-421. doi:10.1016/j.jenvp.2010.04.006

Hand, C., \& Judge, G. (2012). Searching for the picture: forecasting UK cinema admissions using Google Trends data. Applied Economics Letters, 19(11), 1051-1055.

Li, X., Pan, B., Law, R., \& Huang, X. (2017). Forecasting tourism demand with composite search index. Tourism Management, 59, 57-66.

Maller, C., Townsend, M., Pryor, A., Brown, P., \& St Leger, L. (2006). Healthy nature healthy people: contact with nature'as an upstream health promotion intervention for populations. Health promotion international, 21(1), 45-54.

Maples, J. N., Sharp, R. L., Clark, B. G., Gerlaugh, K., \& Gillespie, B. (2017). Climbing out of Poverty: The Economic Impact of Rock Climbing in and around Eastern Kentucky's Red River Gorge. Journal of Appalachian Studies, 23(1), 53-71.

Marion, J. L., Leung, Y.-F., Eagleston, H., \& Burroughs, K. (2016). A review and synthesis of recreation ecology research findings on visitor impacts to wilderness and protected natural areas. Journal of Forestry, 114(3), 352-362.

National Park Service. (2018a). Administrative Boundaries of National Park System Units 9/30/2018. Retrieved from https://irma.nps.gov/DataStore/Reference/Profile/2224545?lnv=True 
This is an author-produced, peer-reviewed version of this article. The final, definitive version of this document can be found online at Journal of Environmental Management, published by Elsevier. Copyright restrictions may apply. doi: 10.1016/j.jenvman.2019.05.006

National Park Service. (2018b). Annual Visitation Summary Report for 2017. Retrieved from https://irma.nps.gov/Stats/SSRSReports/National Reports/Annual Visitation Summary Report (1979 - Last Calendar Year)

National Park Service. (2018c). Welcome to Visitor Use Statistics. Retrieved from https://irma.nps.gov/Stats/

Önder, I., \& Gunter, U. (2016). Forecasting tourism demand with Google trends for a major European city destination. Tourism Analysis, 21(2-3), 203-220.

Park, S., Lee, J., \& Song, W. (2017). Short-term forecasting of Japanese tourist inflow to South Korea using Google trends data. Journal of Travel \& Tourism Marketing, 34(3), 357-368.

Sessions, C., Wood, S. A., Rabotyagov, S., \& Fisher, D. M. (2016). Measuring recreational visitation at U.S. National Parks with crowd-sourced photographs. Journal of Environmental Management, 183, 703-711. doi:10.1016/j.jenvman.2016.09.018

Simmonds, C., Annette, M., Reilly, P., Maffly, B., Wilkinson, T., Canon, G., ... Whaley, M. (2018). Crisis in our national parks: how tourists are loving nature to death. Retrieved from https://www.theguardian.com/environment/2018/nov/20/national-parks-america-overcrowding-crisistourism-visitation-solutions

Steenbergen, M. R., \& Jones, B. S. (2002). Modeling multilevel data structures. American Journal of Political Science, 46, 218-237. doi:10.2307/3088424

Tenkanen, H., Di Minin, E., Heikinheimo, V., Hausmann, A., Herbst, M., Kajala, L., \& Toivonen, T. (2017). Instagram, Flickr, or Twitter: Assessing the usability of social media data for visitor monitoring in protected areas. Scientific reports, 7(1), 17615. doi:10.1038/s41598-017-18007-4

The Pennsylvania State University. (2018). Lesson 1.5: The Coefficient of Determination, r-squared. In STAT 501: Regression Methods. Retrieved from https://onlinecourses.science.psu.edu/stat501/

Vosen, S., \& Schmidt, T. (2011). Forecasting private consumption: survey-based indicators vs. Google trends. Journal of Forecasting, 30(6), 565-578.

Wilmot, N. A., \& McIntosh, C. R. (2014). Forecasting recreational visitation at US National Parks. Tourism Analysis, 19(2), 129-137.

Willmott, C. J., \& Matsuura, K. (2005). Advantages of the mean absolute error (MAE) over the root mean square error (RMSE) in assessing average model performance. Climate research, 30(1), 79-82.

Wood, S. A., Guerry, A. D., Silver, J. M., \& Lacayo, M. (2013). Using social media to quantify nature-based tourism and recreation. Scientific reports, 3, 2976. doi:10.1038/srep02976

Yang, X., Pan, B., Evans, J. A., \& Lv, B. (2015). Forecasting Chinese tourist volume with search engine data. Tourism Management, 46, 386-397.

Ziesler, P. S. (2016). Statistical Abstract: 2015. Retrieved from Fort Collins, CO: https://irma.nps.gov/DataStore/DownloadFile/548275

Ziesler, P. S., \& Singh, P. (2018). Statistical Abstract: 2017. Retrieved from Fort Collins, CO: https://irma.nps.gov/DataStore/DownloadFile/600257 